\title{
Happy birthday Archives of Pediatric Neurosurgery: we are two years old!
}

\author{
Ricardo Santos de Oliveira ${ }^{1}$, Matheus Fernando Manzolli Ballestero ${ }^{1}$, Sergio Cavalheiro ${ }^{1}$
}

${ }^{1}$ Division of Neurosurgery Ribeirão Preto Medical
School, University of São Paulo, São Paulo, Brazil
${ }^{2}$ Department of Medicine, Federal University of
São Carlos, São Carlos, Brazil
${ }^{3}$ Department of Neurosurgery, Universidade
Federal de São Paulo, Brazil
To whom correspondence should be
addressed:
Ricardo Santos de Oliveira, MD
e-mail: rsoliveira30@gmail.com
Available at:
http://www.archpedneurosurg.com.br/

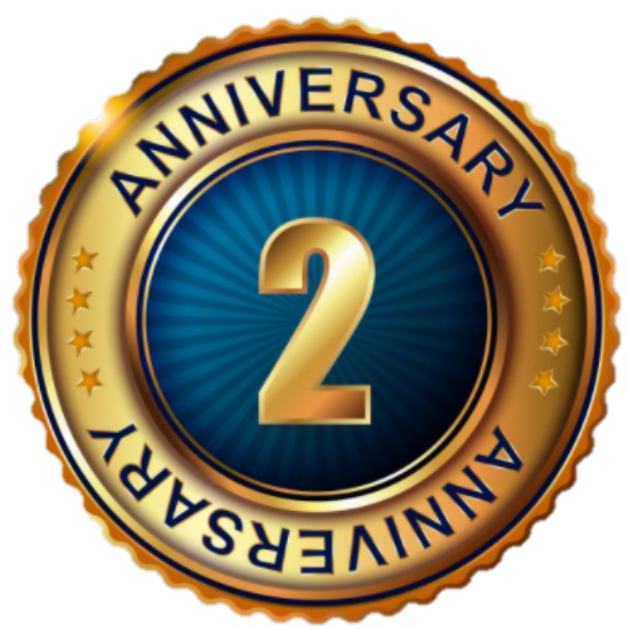

Keyworks: Pediatric neurosurgery, Birthday

An unlikely idea became a reality in June 2019 when we gathered an enthusiastic group and started testing the platform \& workflow by OJS/PKP thus turning an idea into something concrete. The next step would be choosing the name of the journal and creating the website. Finally, the choice of the national and international editorial board based on academic and scientific criteria. Archives of Pediatric Neurosurgery (APN) was born.

We published the very first issue of the APN in September 2019. The decision was to use of the Internet and related technologies as an enabler and infrastructure for health innovations.

The use of information and communication technologies and the web helps to empower patients (not least through peer-to-peer communications), provides a platform for communication, clinical information and telemedicine (these days often through mobile devices), and revolutionizes information access and medical education [1].

We were not only innovating on content, but also on form. We were the first open access electronic-only journal in pediatric neurosurgery, and also, we are on social media as Facebook, Instagram and tweeter. We have different types of publication highlighted the clinical case, video clinical case, and clinical video lecture. Our YouTube channel, together with SBNPed, has a total of 48 videos and more than a thousand inscriptions.

The Archives of Pediatric Neurosurgery is a triannual peer-reviewed medical online journal and was recognized in September 2020 as the official publication of the Brazilian Society for Pediatric Neurosurgery.

We believe APN will contribute in furthering efforts to make our dream a reality getting a pediatric neurosurgery medical journal to be recognize in the world as option to 


\section{Happy birthday Archives of Pediatric Neurosurgery: we are two years old!}

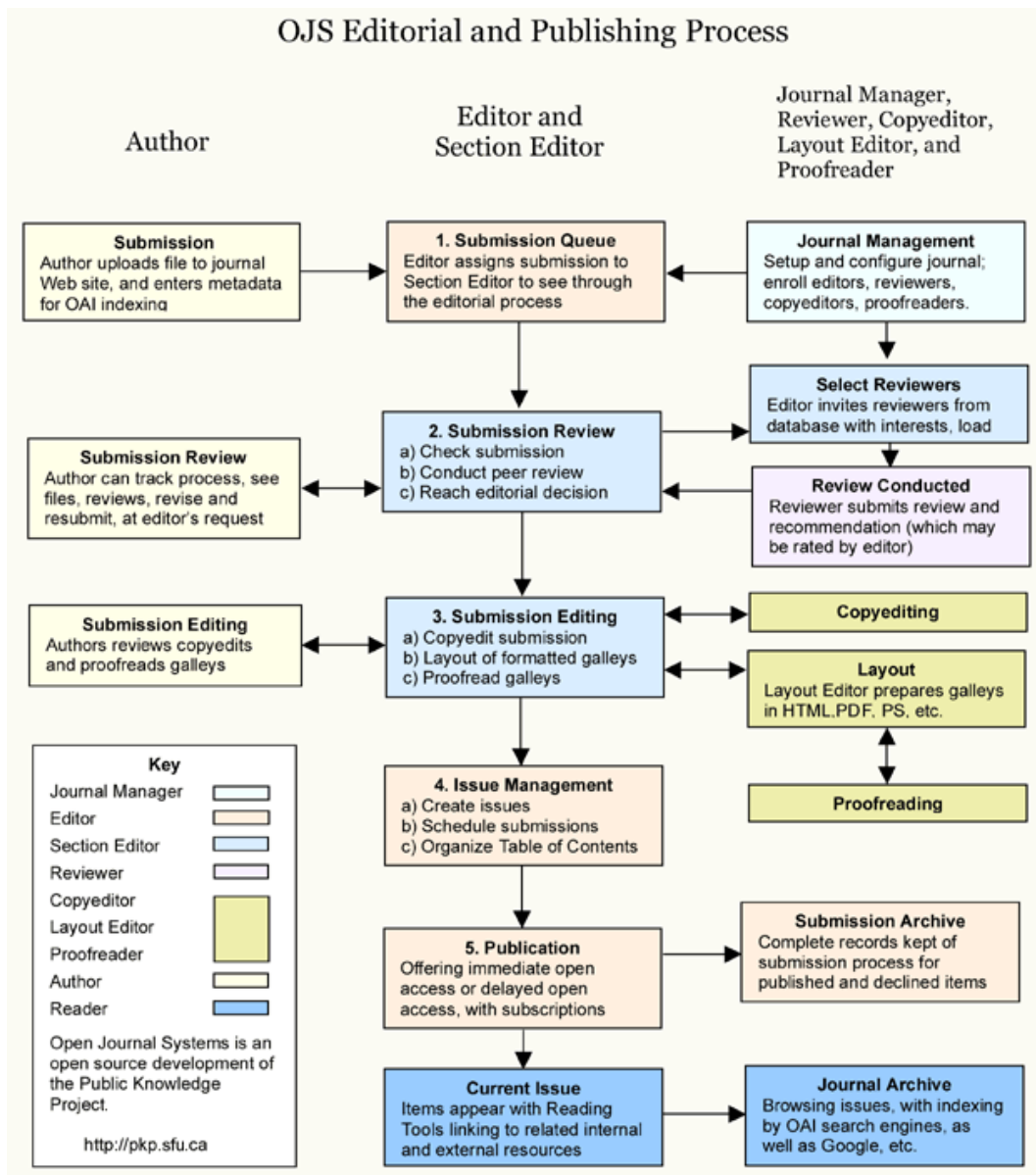

Figure 1 - OJS Editorial and publish process of the APN

publish original papers, clinical case, video clinical case, and others.

Some statistics related to APN:

MOST DOWNLOADED PDF ARTICLE: Dezena et al. Anatomy of the ventricular system: Historical and morphological aspects

MOST READ ABSTRACT: Furlanetti et al. Shunt Technology in Pediatric Neurosurgery: Current options and Scientific Evidence

MOST CITED ARTICLE: de Oliveira RS, Ballestero MFM. The Covid-19 Outbreak and Pediatric Neurosurgery guidelines

\section{Submissions Received: 112}

In two years, APN has published 62 international peerreview medical journals in 5 issues from September, 2019 to August, 2021. All articles are available online and free license to open access and download. All the papers were peer-reviewed (Figure 1).
During this period, we included a specialized consultancy and we were able to index the APN in several indexing bases: Google Scholar, Cengage, REDIB, Crossref, Dimensions, and the most recent J-Gate.

On this special occasion the editorial office would like to extend their greatest appreciation to all editors, and reviewers who have been supportive, and devoted much of their time and effort in nurturing APN. The journal, in particular, would like to thank the authors for placing their faith in this new, bold journal when it was still in its beginning stages. This continuous support has been pivotal to the development of the journal.

In the times to come, APN will remain committed to publishing novel, high-quality, and valuable content. APN endeavors to bring readers the most up-to-date information in a wide variety of fields in the hopes of ultimately benefiting patients, all while ensuring the largest possible readership for all articles published in the journal. 


\section{Happy birthday Archives of Pediatric Neurosurgery: we are two years old!}

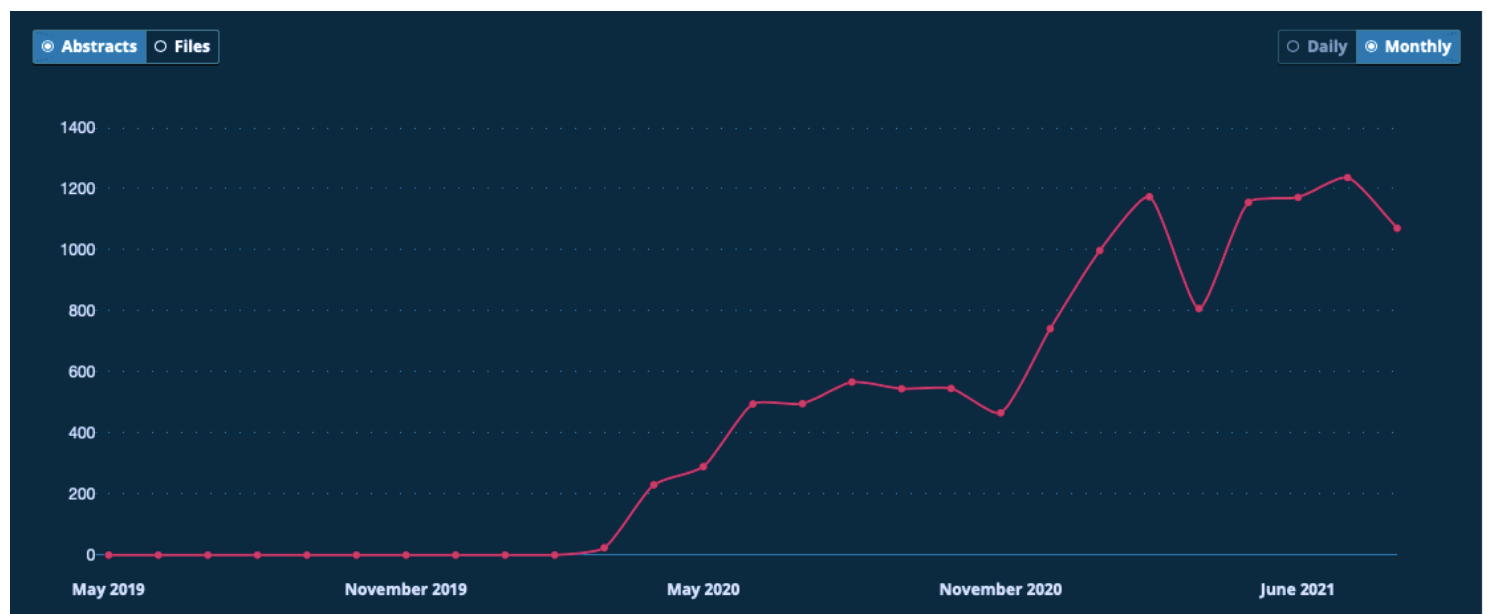

Figure $\mathbf{2}$ - Abstracts views of $A P N$ website in the past two years.

In our modern globalized academic community, APN recognizes the importance of international collaborations, and seeks to promote itself as an international journal. We have organized a series of articles focusing on important topics in various fields, and invited international prominent experts to co-author.

Based on data from Google Analytics, APN is gaining momentum and attracting interest from readers. The number of accesses to abstracts has been increasing progressively since 2019 (Figure 2).

As Section Editors, they keep track of the latest and significant research in their areas and recommend international key opinion leaders to review and write editorial comments on those important topics.
We will pursue the serious work and include the APN in more indexing databases, expanding its importance in pediatric neurosurgery.

Yes, it's time to celebrate this incredible achievement! but continue the professional work.

\section{Happy Birthday Archives of Pediatric Neurosurgery! A long life for everyone!}

\section{REFERENCE}

1. Eysenbach G. Pleasing both authors and readers. From ELPS to hypER papers. BMJ 1999 Aug 28;319(7209):579580 